\title{
PRÁTICA DE LEITURA E ESCRITA EM AMBIENTE VIRTUAL: UMA ANÁLISE INDICIÁRIA DO PROCESSO DE ALFABETIZAÇÃO MEDIADO PELO LIVRO INFANTIL
}

\author{
READING AND WRITING PRACTICE IN A VIRTUAL ENVIRONMENT: AN EVIDENTIARY \\ ANALYSIS OF THE LITERACY PROCESS MEDIATED BY CHILDREN'S LITERATURE
}

\author{
PRÁCTICA DE LECTURA Y ESCRITURA EN EL ENTORNO VIRTUAL: UN ANÁLISIS \\ INDICATIVO DEL PROCESO DE ALFABETIZACIÓN MEDIADO POR EL LIBRO INFANTIL
}

\author{
Gabriele Damin de Souza1 \\ Fabiana Giovani 2
}

\begin{abstract}
RESUMO
À luz da perspectiva teórica proposta por Mikhail Bakhtin e seu Círculo de estudos, que concebe a linguagem como meio de interação social, voltamos nosso olhar para o texto produzido por sujeitos social e historicamente situados e propomos desenvolver um exercício prático, que permita a investigação do papel do livro infantil no processo de apropriação da modalidade escrita da língua em contexto digital. Nesta proposta, assumimos que a leitura se caracteriza como interlocução entre leitor e escritor, sendo 0 resultado deste diálogo a constituição tanto dos sentidos do texto que foi lido, quanto dos indivíduos que dele participaram ativamente. Partimos, portanto, do pressuposto de que os sentidos do texto escrito são constituídos de maneira dialógica, para perceber, por meio de um exercício de aplicação, como uma criança de sete anos, que no ano de 2021 cursa o segundo ano do Ensino Fundamental, ou seja, em processo de alfabetização, apropria-se da palavra do outro para construir sua própria escrita. Considerando as limitações impostas pela pandemia causada pelo vírus Covid-19, este exercício realizou-se em ambiente virtual, através da plataforma WebConf, sendo dividido em um momento de leitura do livro infantil "A Visita" - escrito e ilustrado por Antje Damm - e de um momento de produção escrita. Como resultado desta interação temos a produção da criança, cuja análise - guiada pela metodologia do Paradigma Indiciário (GINZBURG, 1989) - mostra que é possível trabalhar com as obras literárias, a partir de uma perspectiva enunciativa, dentro do ambiente digital estimulando a apropriação ativa e responsiva da linguagem escrita.
\end{abstract}

PALAVRAS CHAVE: Leitura. Escrita. Literatura infantil. Estudos bakhtinianos. Paradigma indiciário.

\begin{abstract}
In accordance with the theoretical perspective proposed by Mikhail Bakhtin, which sees language as a medium of social interaction, we turn our gaze to the text produced by subjects socially and historically situated and propose to develop a practical exercise, which allows the investigation of the role of the children's literature in the process of appropriation of the written modality of the language in a digital context. In this proposal, we assume that reading is characterized as an interlocution between reader and writer, and the result of this dialogue is the constitution of both the meanings of the text that was read, and the individuals who actively participated in it. Therefore, we assume that the meanings of the written text are constituted in a dialogical way, to realize, through an application exercise, how a seven-year-old child, who in the year 2021 is in alphabetization process, appropriates the words of others to build their own writing. Considering the limitations imposed by the Covid-19 pandemic, this exercise took place in a virtual environment, via WebConf platform, being divided into a moment of Reading, with the book "The Visit" written and illustrated by Antje Damm - and a moment of writing. As a result of this interaction, the analisis of the child's production - guided by the methodology of the Evidenciary Paradigm (GINZBURG, 1989) shows that it is possible to work with literary texts, from an enunciative perspective, within the digital environment stimulating the active and responsive appropriation of written language.
\end{abstract}

1 Universidade Federal de Santa Catarina. E-mail: gdamindesouza@gmail.com

2 Universidade Federal de Santa Catarina. E-mail: fabiana.giovani@ufsc.br

Revista de Ciências Humanas, Frederico Westphalen - RS, v. 22, n.2, p. 27-44, maio/ago. 2021.

\begin{tabular}{l|l} 
Recebido em: 03/05/2021 & Aceito em: 27/06/2021
\end{tabular} 
KEY WORDS: Reading. Writing. Children's Literature. Bakhtinian Studies. Evidenciary Paradigm.

\section{RESUMEN}

Partiendo de la perspectiva teórica bajtiniana, que concibe el lenguaje como un medio de interacción social, dirigimos nuestra mirada al texto producido por sujetos social e históricamente situados y nos proponemos desarrollar un ejercicio práctico, que permita investigar el papel del libro infantil en el proceso de alfabetización en un contexto digital. En esta propuesta, asumimos que la lectura se caracteriza por ser una interlocución entre el lector y el escritor, y el resultado de este diálogo es la constitución tanto de los significados del texto que se leyó, como de los individuos que participaron activamente de él. Partimos, por tanto, del supuesto de que los significados del texto escrito se constituyen de forma dialógica, para realizar, a través de un ejercicio de aplicación, cómo un niño de siete años, que en el año 2021 está en proceso de alfabetización, se apropia de la palabra del otro para construir su propia escritura. Teniendo en cuenta las limitaciones impuestas por la pandemia causada por el virus Covid-19, este ejercicio tuvo lugar en un entorno virtual, a través de la plataforma WebConf, dividiéndose en un momento de lectura del libro infantil "La visita" -escrito e ilustrado por Antje Damm- y un momento de producción escrita. Como resultado de esta interacción tenemos la producción del niño, cuyo análisis guiado por la metodología del Paradigma Indicativo (GINZBURG, 1989)- muestra que es posible trabajar con obras literarias, dentro de una perspectiva enunciativa, en el entorno digital estimulando la apropiación activa y responsiva del lenguaje escrito.

PALABRAS CLAVE: Lectura. Escrita. Literatura Infantil. Estudios Bajtinianos. Paradigma Indicativo.

\section{CONSIDERAÇÕES INICIAIS}

A leitura verdadeira me compromete de imediato com o texto que a mim se dá e a que me dou e de cuja compreensão fundamental me vou tornando também sujeito. Ao ler não me acho no puro encalço da inteligência do texto como se fosse ela produção apenas de seu autor ou de sua autora (Paulo Freire).

Situando nossa pesquisa na perspectiva filosófica proposta por Mikhail Bakhtin e seu Círculo de estudiosos, propomos desenvolver e analisar um exercício prático realizado em ambiente virtual com uma criança de sete anos, a fim de compreender como o livro infantil pode contribuir na formação de leitores em processo de alfabetização durante a pandemia causada pelo vírus Covid-19. Dessa maneira, filiamo-nos à teoria bakhtiniana e concebemos a linguagem como um meio de interação entre indivíduos social e historicamente situados. Retomando as palavras de Paulo Freire - que abrem este trabalho - definimos como leitura um ato de interlocução, em que o leitor assume papel ativo e constitutivo diante das palavras do escritor: respondendo a elas e atribuindo-Ihes sentido a partir do lugar que ocupa no mundo. No bojo desse encontro de vozes, mediado pelo texto, estão, pois, sujeitos reais e suas vivências que dialogam e o resultado desta interação é a construção de sentidos para o texto escrito. Por isso,

[...] o leitor quando envolvido numa relação de interação com a obra literária, encontra significado quando lê, procura compreender o texto e relaciona com 0 mundo à sua volta, construindo e elaborando novos significados do que foi lido. Só assim, a leitura pode contribuir de forma significativa numa sociedade letrada, no 
exercício da cidadania e no desenvolvimento intelectual (PAIVA; OLIVEIRA, 2010, p.32).

Isto posto, considerando nossa escolha teórico-filosófica, encaramos o processo de alfabetização como o período em que os indivíduos apropriam-se não somente da modalidade escrita da língua, mas de um instrumento cultural, "[...] que faculta a instituição de relações intersubjetivas, por meio das quais os sujeitos monitoram suas vivências com a escrita no cotidiano, tanto quanto ampliam essas mesmas vivências no que respeita ao grande tempo" (CERUTTI-RIZZATTI, 2016, p.1, grifos da autora). Portanto, apreender aspectos da língua escrita para desenvolver habilidades de codificação e decodificação não deve ser o único fim para o trabalho de alfabetizar.

Não defendemos com isso a abolição de estratégias que esclareçam questões próprias do sistema linguístico da modalidade da língua da qual a criança está se apropriando, ao contrário, assumimos uma posição que privilegia a construção de práticas de leitura e escrita que possibilitem tanto a reflexão sobre os usos reais da linguagem quanto a entrada do alfabetizando em determinadas esferas letradas da atividade humana dominando o que é denominado de norma. Para que isso seja possível, acreditamos que o melhor caminho a ser seguido é o que tem o texto como ponto de chegada e de partida. Assim,

\begin{abstract}
[...] desenvolver um trabalho inscrito no interior da linguística da enunciação propicia que a criança, em fase de alfabetização, aproprie-se não só do sistema alfabético de escrita, mas, compreenda e manifeste significativo conhecimento e principalmente autonomia com relação aos gêneros discursivos que circulam em nossa sociedade que é, segundo Bakhtin, a forma de manifestação da língua em enunciados, orais ou escritos, concretos e únicos, oriundos de sujeitos que circulam por inúmeras esferas da atividade humana [...] (GIOVANI, 2006, p.127-128).
\end{abstract}

Diante de tudo o que foi exposto até então, delineamos nossa proposta. Fundamentadas na arquitetônica bakhtiniana, desafiamo-nos a investigar o papel do livro infantil no processo de apropriação da modalidade escrita da língua, como meio de promover o contato entre criança e cultura letrada. Frente às limitações impostas pelo momento atípico em que vivemos, desenvolvemos um exercício prático, aplicado em ambiente virtual, composto de práticas de leitura e escrita com uma criança de sete anos em período de alfabetização. Para esta proposta de intervenção, selecionamos o livro intitulado "A Visita", escrito e ilustrado pela arquiteta alemã Antje Damm³.

\footnotetext{
${ }^{3}$ O livro "A Visita", publicado no Brasil em 2016 pela editora Companhia das Letrinhas, foi um dos livros que compuseram o catálogo da campanha "Leia para uma Criança" desenvolvida pelo Itaú Social, que distribui livros em todo o território brasileiro mediante cadastro na plataforma online do site. $\mathrm{O}$ 
Nossa escolha baseia-se no pressuposto de que o livro infantil configura-se como um gênero discursivo cuja principal destinatário é a criança. Dessa forma, "[...] a Literatura Infantil contribui para a formação do leitor literário quando a obra-literária propõe indagações ao leitor, estimulando a curiosidade e, instigando assim, a produção de novos conhecimentos" (PAIVA; OLIVEIRA, 2010, p.34). Acrescentamos à nossa justificativa para esta seleção o que enumera Queiroz (2012, p.31): ao escolher um livro infantil para ser trabalhado com crianças em alfabetização é necessário considerar, além das ilustrações e projeto gráfico, o modo como a linguagem escrita dialoga com a linguagem não escrita dentro da obra, bem como, considerar de que maneira o livro estimula uma interlocução entre o leitor e a sua realidade, suscitando a construção ativa de seus sentidos. Como produto desta atividade, temos a produção escrita da criança, que será analisada por meio da metodologia do paradigma indiciário, desenvolvida pelo historiador Carlo Ginzburg (1989).

Em síntese, este artigo compreende uma reflexão acerca do papel da literatura infantil no processo de apropriação da modalidade escrita e, por consequência, na formação de leitores dentro do contexto digital. Para dar conta desta proposta, organizamos este trabalho em três seções: dedicamos à primeira seção delimitar nossas escolhas teóricas e, assim, discorrer acerca dos pressupostos da teoria bakhtiniana que embasam nosso trabalho com o texto escrito, além de conceituar o livro infantil como gênero discursivo destinado às crianças e seu papel na alfabetização, tendo em vista a teoria enunciativa dentro da qual nos inscrevemos. Já na seção seguinte, pretendemos apresentar a metodologia que nos permitiu analisar a produção escrita da criança de maneira contextualizada e singular. Por fim, na última seção, relatamos e refletimos sobre a prática de leitura e escrita desenvolvida.

\section{DELIMITANDO AS ESCOLHAS TEÓRICAS}

As contribuições de Mikhail Bakhtin e seu Círculo de estudiosos para o campo das ciências humanas - em especial da literatura, da linguística e da filosofia da linguagem - são imprescindíveis. Os filósofos russos inauguram com seus escritos uma nova maneira de conceber e estudar a linguagem, explorando-a como um produto social e um meio de interagir dentro dos mais diversos campos e esferas da atividade humana (BAKHTIN, 1997). Esta perspectiva evidencia o diálogo como "[...] forma clássica de comunicação discursiva" (BAKHTIN,

objetivo desta campanha é democratizar o acesso a livros de literatura infantil, enviando obras selecionadas às escolas, às regiões vulneráveis do País, bem como a bibliotecas e a todos que fizerem o pedido. Site da campanha:<https://www.euleioparaumacrianca.com.br/leia-para-uma-crianca/>. 
1997, p.275) e os enunciados - orais e/ou escritos, pertencentes aos sujeitos do discurso como unidades reais desta comunicação. Acerca disso, Bakhtin (1997, p.274) escreve: "[...] o discurso só pode existir de fato na forma de enunciações concretas de determinados falantes sujeitos do discurso. 0 discurso sempre está fundido em forma de enunciado pertencente a um determinado sujeito do discurso e fora dessa forma não pode existir”. Partimos destas proposições para refletir acerca da apropriação da escrita em contexto digital e como a literatura infantil pode contribuir para a formação destes que estão apre(e)ndendo a cultura letrada e se constituindo dentro dela.

O texto como local de diálogos: a leitura e a escrita a partir da teoria bakhtiniana

Em linhas gerais, Bakhtin (1997) afirma que os enunciados organizam o discurso e apresentam formas relativamente estáveis - os gêneros discursivos - definidas por meio do contexto situacional em que se inserem. Compreender esta unidade discursiva e sua conceituação dentro da teoria bakhtiniana é imprescindível, pois "[...] é justamente a partir do enunciado que é possível pensar as categorias texto, leitura e leitor" (INDURSKY, 2010, p.167). Nesse sentido, a linguística da enunciação nos permite estudar o livro infantil como forma concreta de enunciado, passível de leitura e, portanto de resposta, isto é, como elo da cadeia discursiva ${ }^{4}$, que possui autor e destinatário ${ }^{5}$. Assumimos, assim, que um texto só pode ser interpretado e plenamente compreendido quando contextualizado em determinado evento comunicativo (INDURSKY, 2010) e quando colocado em contato com outros textos, pois, como esclarece Bakhtin (2017, p.67, grifos nossos): "um texto só tem vida contatando com outro texto (contexto). Só no ponto desse contato de textos, eclode a luz que ilumina restrospectiva e prospectivamente, fazendo dado texto comungar no diálogo. [...] Por trás desse contato está 0 contato entre indivíduos e não entre coisas [...]". Com isso, concluímos que todos os textos são únicos e singulares enquanto enunciados concretos, produzidos por sujeitos, também únicos e singulares, em um determinado contexto de enunciação.

\footnotetext{
${ }^{4}$ Retomamos aqui a reflexão proposta por Bakhtin (1997, p.299), em que ele pressupõe que "cada enunciado é um elo na cadeia da comunicação discursiva. Ele tem limites precisos, determinados pela alternância dos sujeitos do discurso (dos falantes), mas no âmbito desses limites, o enunciado [...] reflete o processo do discurso, os enunciados dos outros, e antes de tudo os elos precedentes da cadeia (às vezes os mais imediatos, e vez por outras até os muito distantes - os campos da comunicação cultural)".

${ }^{5}$ Ao caracterizarmos o livro infantil como forma relativamente estável do discurso - ou seja, como gênero discursivo -, assumimos que um dos traços que o constitui como tal é o seu endereçamento. Segundo Bakhtin (1997, p.301), "um traço essencial (constitutivo) do enunciado e o seu direcionamento a alguém [...], o enunciado tem autor [...] e destinatário".
} 
Um texto é um objeto material que, ao ser tomado como o texto produzido por um sujeito, torna-se um enunciado, algo proferido em contexto e portanto endereçado, dirigido a outros sujeitos, parte de um processo de instauração de sentidos cujas "marcas" estão em sua própria materialidade! O texto traz potenciais de sentido, é uma materialidade com a qual são instaurados sentidos a partir da produção do discurso. (SOBRAL, 2012, p.34, grifos nossos).

À luz do pressuposto de que os sentidos do texto constituem-se dialogicamente, voltamo-nos para 0 ato de ler, a fim de compreendê-lo como interlocução. $O$ leitor, na concepção dialógica, assume papel ativo e responsivo diante do texto, isso significa que suas interpretações configuram-se como respostas ao que foi escrito. Acerca disso, Indursky (2010, p.168) aponta que "o leitor não apenas extrai os significados postos no texto pelo locutor/autor, mas, ao ultrapassar os limites físicos do texto, ele também Ihe atribui sentidos". O diálogo entre estas duas partes - leitor e escritor - (re)define o texto escrito atribuindo a ele sentidos e significados que refletem e refratam a realidade. Assim sendo, "[...] 0 ato de leitura está repleto de significados que não se esgotam entre a palavra escrita e o leitor. 0 encontro entre a palavra e 0 sujeito que lê estabelece uma experiência que pode modificar a concepção que ambos têm do mundo e das suas próprias existências." (CARVALHO, 2014, p. 173).

Dado 0 exposto, ao pesquisar o texto a partir da arquitetônica bakhtiniana, percebemos que ele não é fechado, isto é, não acaba quando seu autor o finaliza, ao contrário: abre uma janela infinita que dá acesso aos enunciados que o precederam $e$ - dentro dos limites possíveis de respostas que podem ser dadas a ele pelos seus leitores - aos enunciados que surgem/surgirão a partir dele.

Ao ler, o homem escreve um novo texto, pois a capacidade que o homem tem de
interferir e modificar por meio da sua palavra torna o texto tão dinâmico que, tantos
textos existirão quantas forem as leituras feitas sobre o texto original. Não existirá
mais um autor apenas. Através da leitura cada leitor será um novo autor e o discurso
primeiro poderá modificar-se tantas vezes quanto forem suas interpretações
(FAZENDA, 2013, p.57).

Por conseguinte, a escrita é permeada de um caráter responsivo, em que se inscrevem a subjetividade e a multiplicidade de sentidos que podem ser atribuídos ao texto em construção. Dentro desta perspectiva "[...] a escrita adquire função de suma importância, porque, além de seu papel documental de guardiã da tradição, ela é instância instauradora de diálogos nas várias dimensões espaciais e temporais" (BRANDÃO, 2005, p.273). Aprender a escrever, portanto, vai para além de desenvolver habilidades de codificação. Escrever é colocar em prática a linguagem, é constituir-se por meio da enunciação e dialogar com a realidade. 


\section{O papel do livro infantil na alfabetização}

Alfabetizar é, antes de mais nada, um trabalho que visa a inserção dos sujeitos na cultura letrada. Vivemos, pois, em uma sociedade grafocêntrica - centrada na escrita - e, por isso, torna-se imprescindivel munir os indivíduos com o que é necessário para que eles circulem dentro dos mais diversos campos da atividade humana. Segundo Cerutti-Rizzati (2016, S.n.) "[...] alfabetizar implica criar condições para que os sujeitos se apropriem do sistema de escrita alfabética, fazendo-o no âmbito dos usos sociais dessa modalidade da língua, o que significa compreender que o processo de alfabetização precisa se dar no escopo dos gêneros do discurso". Se se apropriar da linguagem escrita garante ao sujeito a entrada em determinadas esferas da sociedade, incumbe-se à alfabetização dar subsídios para que os indivíduos assumam seu papel como sujeitos partícipes do mundo. Isso significa que

[...] a alfabetização não implica apenas a aprendizagem da escrita de letras, palavras ou orações. Tampouco envolve simplesmente uma relação da criança com a escrita. Dessa forma, a criança pode escrever para si mesma, palavras soltas ou listas para não esquecer ou para organizar o que já sabe. Pode ainda, tentar escrever um texto, mesmo que fragmentado, para narrar, registrar ou apenas dizer. 0 importante é saber que essa escrita necessita ser, incondicionalmente, permeada por um sentido, por um desejo, além de implicar ou pressupor, sempre, um interlocutor (GIOVANI, 2019, p.59).

Colocando em evidência a linguagem escrita como produto humano e instrumento cultural, é inegável seu papel social e político, como destaca Goulart (2014, p.44) "[...] a escrita atravessa a vida social, as nossas vidas particulares, de uma infinidade de maneiras". Sabendo que nos apropriamos da linguagem na forma de enunciados relativamente estáveis, deve-se proporcionar, durante o processo de alfabetização, o contato da criança com os gêneros discursivos e isso só é possível através da prática de leitura e escrita. Como consequência disso, o trabalho com o texto escrito deve ser pautado na construção de sentidos e na reflexão dos usos reais da linguagem, dessa forma dar-se-á conta de trabalhar o sistema linguístico sem distanciá-lo da realidade.

Desenvolver práticas de leitura meramente operacionais levaria o leitor ao desenvolvimento de habilidades que desencadeariam uma leitura analista, crítica? Ou seria indispensável desenvolver práticas que permitam aos cidadãos exercer 0 poder sobre a linguagem e, por meio, dela, pensar a experiência e compreender alguns dos modos pelos quais o mundo opera, como propõe Silva (1998, p.34)? Dentro dessa proposta, a literatura seria um instrumento indispensável para 0 desenvolvimento de tais práticas e habilidades, pois o texto ficcional ou poético requer do leitor interpretações, correlações, apropriações que lhe permitem compreender, simultaneamente, a vida, o mundo, a existência, a identidade, a alteridade (QUEIROZ, 2012, p.34). 
Nessa perspectiva, retomamos o que discorre Queiroz (2012, p.38-39), para refletir acerca do papel do livro de literatura infantil no período de alfabetização. A autora, apoiada no que escreve Rildo Cosson (2006), concebe a literatura como instrumento que possibilita ao leitor em formação não somente dominar o código escrito, mas acessar a dimensão cultural e estética da linguagem, o que viabiliza explorar "leituras que extrapolam o próprio texto". Complementando isso, trazemos os apontamentos de Camargos e Giovani (2020, p.178), acerca da leitura como decodificação. Pensando na relação entre fala e escrita, os autores voltam-se para o que escrevem Corrêa e Komesu e refletem:

[...] seja na fala ou na escrita, a leitura por decodificação se baseia na ideia de que 0 sentido está codificado no texto, fato que levaria ao fechamento do sentido nos limites da organização verbal deste texto. No entanto, não basta dominar a língua para a leitura do texto, já que este é atravessado não só pelo conhecimento/domínio da língua, mas também pela história e, principalmente, pelos sujeitos.

O livro infantil é colocado nessa dinâmica como o gênero discursivo que se destina à criança e, portanto, insere-se no processo de apropriação da escrita como um espaço lúdico de interlocução. Para a leitura do texto, a criança que está apre(e)ndendo a linguagem escrita não o decodifica, somente, mas se apropria dele para construir os seus sentidos.

Considerar a criança como sujeito autor em constituição, que se apropria do texto escrito na/a partir da interação com a escrita e, principalmente, com o outro, é compreender melhor as representações dos aprendizes sobre o texto escrito, as hipóteses que eles (re) elaboram, as particularidades e convergências de seus percursos marcados por uma subjetividade socialmente constituída, como postulam Bakhtin e Vygotski (GIOVANI, 2009, p.19).

Em suma, podemos caracterizar o livro infantil como gênero em que palavra e imagem contam histórias (FERREIRA; LINO DE ARAÚJO, 2015). Tendo isso em vista, quando propomos desenvolver uma prática de leitura e escrita fundamentadas na teoria discursiva, que tem como base os escritos do Círculo de Bakhtin, defendemos o trabalho com o texto, como espaço de encontro entre sujeitos. A alfabetização sob a ótica dessa teoria, não se limita ao desenvolvimento de habilidades de decodificação e codificação da língua em sua modalidade escrita, mas como um processo de apropriação dos usos reais da linguagem.

\section{O CAMINHO PERCORRIDO: ESCOLHAS METODOLÓGICAS}


Tendo em vista a teoria que embasa este trabalho, estabelecemos como objeto de pesquisa o texto escrito pelo sujeito que é ser expressivo e falante 6 . Diante disso, percebemos a importância de adotar uma metodologia que dialogue com os pressupostos que fundamentam este artigo. Não obstante, inserindo nossa pesquisa no âmbito das ciências humanas, voltamos nosso olhar para os enunciados concretos produzidos por sujeitos reais e propomos analisar de maneira profunda e rigorosa a sua singularidade. Como escreveu Bakhtin $(2017$, p.58) "aqui 0 critério não é a exatidão do conhecimento, mas a profundidade da penetração. Nesse caso 0 conhecimento está voltado para o individual". A questão que se coloca a partir desta reflexão é exatamente qual caminho percorrer para que a pesquisa que propomos desenvolver preserve a voz do ser que fala e se expressa por meio do seu texto.

Nossa escolha metodológica reflete, portanto, um posicionamento heterocientífico face ao objeto em análise. Isso significa que abandonamos uma posição epistemológica que "[...] admite como científico (e verdadeiro dentro de cada teoria) o enunciado relativo àquilo que se repete, àquilo que é imutável, àquilo que é produto da abstração deduzidas todas as particularidades, todas as singularidades como 'desvios' não significativos da realidade concreta" (GERALDI, 2012, p.20), para estudar as infinitudes da linguagem. Para tanto, faz-se necessário uma metodologia - não um método (GERALDI, 2012) - que nos permita debruçar sobre a complexidade do enunciado para interpretá-lo sem generalizá-lo ou monologizá-lo.

Em consonância com o que aponta Geraldi (2012, p.35), adotamos o paradigma indiciário - modelo epistemológico emergido no âmbito das ciências humanas, explorado e definido, principalmente, pelo historiador Carlo Ginzburg (1989) - como caminho metodológico. Este paradigma parte da percepção e investigação de indícios que, como pistas decifradas por um detetive, podem revelar fenômenos da realidade.

As raízes do paradigma indiciário são antigas: remontam à época em que o ser humano rastreava sua presa a partir de pegadas na lama, registrando, interpretando e classificando pistas (indícios) de onde poderia encontrar sua caça. Este conhecimento milenar foi repassado por gerações através da contação de fábulas. Dessa maneira, o saber venatório (de caça) constitui-se como um conhecimento que permite a reconstrução de fatos a partir da observação. Sobre isso, Ginzburg (1989, p.152) escreve: "o caçador teria sido o primeiro a 'narrar uma história' porque era o único capaz de ler, nas pistas mudas (se não imperceptíveis) deixadas pela presa, uma série coerente de eventos". A observação e análise de indícios possibilita ao

\footnotetext{
${ }^{6}$ Retomamos aqui o que escreve Bakhtin (2017, p.59): “o objeto das ciências humanas é o ser expressivo e falante. Esse ser nunca coincide consigo mesmo e por isso mesmo é inesgotável em seu sentido e significado".
} 
observador recolher pistas do evento ao qual se dispõe a interpretar e, a partir delas, capacita-0 a descrever e narrar acontecimentos mesmo não estando envolvido neles.

Trazendo o que é proposto por Ginzburg (1989) para o nosso trabalho com a linguagem, mais especificamente, com o texto produzido por uma criança em alfabetização, ratificamos que

\begin{abstract}
Os indícios que rastreamos e que direcionam o nosso olhar a alguma interpretação, não é sinônimo de exatidão. Por lidarmos com produções de sujeitos reais, o ser que se auto-revela nas escritas não pode ser forçado nem tolhido. O ser é livre e por isso não apresenta nenhuma garantia. Assim o conhecimento que nos é possível construir não pode dar nada nem garantir uma certeza, como fato estabelecido com precisão e dotado de importância prática e única para a nossa vida (GIOVANI, 2010, p.120).
\end{abstract}

Ao adotar o paradigma indiciário como metodologia, propomos coletar os indícios do evento que está sendo investigado - a prática de leitura e escrita com/de uma criança de sete anos - e, através da abdução, isto é, da formulação de hipóteses, construir sentidos provisórios para o fenômeno em análise. Seguindo o raciocínio abdutivo, a hipótese formulada nos guiará a novos indícios que, como em uma colcha de retalhos, vão sendo costurados até formarem um retrato possível do que é estudado. "Agindo assim sucessivamente, como um detetive, chega-se a um sentido construído com base em argumentos coerentes e consistentes. Este sentido não esgota os sentidos possíveis - que são inacabáveis - mas é aquele a que se chegou operando com os dados disponíveis no momento da pesquisa" (GERALDI, p.35). Como pesquisadoras, construímos nossa interpretação do lugar em que falamos e através das escolhas que fazemos.

Em linhas gerais, considerando as limitações impostas pela pandemia causada pelo vírus Covid-19, desenvolvemos um exercício prático realizado em ambiente digital através da plataforma WebConf. Esta atividade foi, portanto, dividida em dois momentos: um dedicado à leitura e outro em que se propôs a produção de um texto escrito. Nosso trabalho pautou-se, principalmente, nos eixos de leitura e escrita propostos por Geraldi (2010a) e o resultado desta interação - o texto escrito - foi analisado por meio da metodologia acima explicitada.

Assim, a leitura do livro "A Visita" - escrito e ilustrado por Antje Damm - foi realizada em uma manhã de terça-feira para uma criança de sete (7) anos,- nascida no dia 7 de novembro de 2013, aqui chamada de L. - e que, no ano de 2021, cursa o segundo ano do Ensino Fundamental (anos iniciais). Neste momento de interação mediada pelo texto, pudemos colocar em prática o ensino como um acontecimento (GERALDI, 2010b): partimos de perguntas para que o sujeito em processo de alfabetização construísse suas respostas a partir da leitura de um livro infantil. Isto posto, antes de voltarmo-nos para o produto desta experiência, consideramos necessário reconstruir o cenário desta interlocução, relatando brevemente sobre como ocorreu 
este encontro de vozes e realidades para podermos refletir acerca da apropriação da palavra escrita, possibilitada pela literatura, mesmo em meio digital.

\section{PRÁTICA DE LEITURA E ESCRITA: RELATO E REFLEXÕES}

Relato de leitura: interlocução mediada pelo texto

Câmeras e microfones ligados, assim inicia o diálogo. $\mathrm{Na}$ tela da sala virtual, o livro selecionado ganha novo formato: as páginas antes folheadas tornam-se slides, a capa colorida que convida o leitor para a experiência de leitura, nesta interação é a imagem reconhecida pela criança. Feitas as apresentações, criança e pesquisadoras iniciam a interação, dá-se uma breve explicação de como a dinâmica da atividade funcionaria naquela manhã, o livro é "aberto" e a prática de leitura inicia. Em síntese, o enredo da narrativa se desenvolve a partir do encontro de duas personagens: Elise - uma senhora medrosa e solitária, que nunca sai de casa - e Emil uma criança.

Elise é uma mulher muito medrosa. Tem medo de aranha, medo de gente e até medo de árvore. Por isso vive sozinha e sozinha pretende ficar. Mas quando menos espera, um aviãozinho de papel entra por uma janela. No dia seguinte, certa visita bate em sua porta. E agora, o que fazer? Será que ela deve receber um estranho em sua casa - e abrir um espaço como essa em sua vida? (DAMM, 2016, contracapa).

Tematizando a solidão, o medo, o envelhecimento e a amizade, Antje Damm dialoga, em seu livro, com a vida, e este contato - entre literatura e realidade - pode ser percebido através das cores que tingem as suas ilustrações (Imagens 1 e 2). A dinâmica entre a linguagem não verbal e a linguagem verbal é interpretada pela criança, que durante a prática de leitura aponta: quando a personagem Emil entra na casa de Elise, esta vai ficando mais clara e colorida.

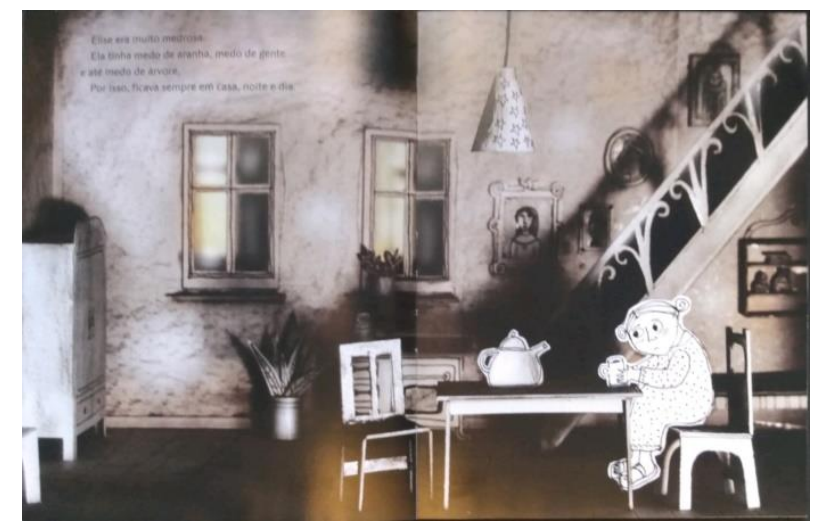

FIGURA 1 - Primeiras páginas do livro Fonte: retirado de DAMM (2016) pelas autoras. 


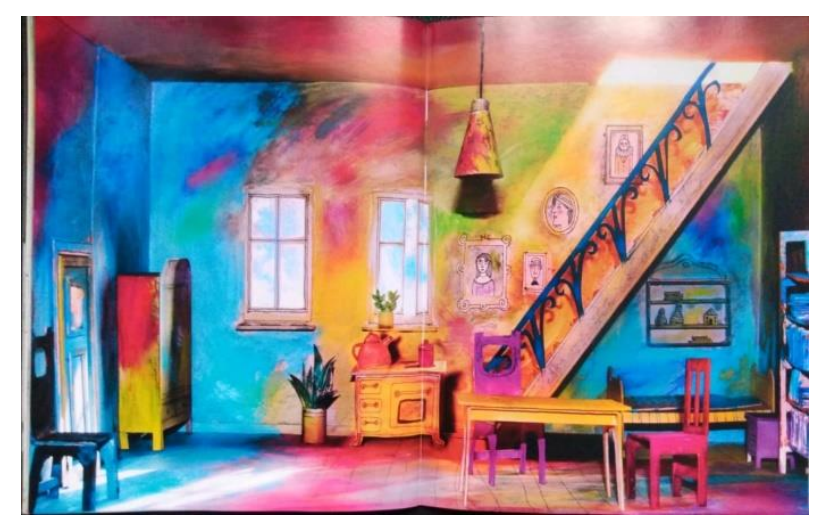

FIGURA 2 - Últimas páginas do livro

Fonte: retirado de DAMM (2016) pelas autoras.

Não obstante, dando sequência ao nosso relato de interação, percebemos que L. presta atenção nas imagens que the são mostradas na tela e escuta atentamente à leitura que as pesquisadoras fazem. Em determinado momento da narrativa, L. associa este movimento de mudança de cores - de tons acinzentados para tons de rosa, amarelo azul e verde - ao fato das personagens estarem brincando e, nesse momento de brincadeira com Emil, Elise perde o medo que tinha. Assim, o ato de ler como interlocução mediada pelo texto é posto em prática neste ambiente digital. Ali se instaura uma conversa sobre a narrativa, com a criança retomando as partes do livro que mais the chamaram atenção, relembrando as personagens e dando detalhes sobre as ilustrações que acompanharam a história.

Após uma breve discussão sobre o livro, entra-se na proposta de produção escrita. Para isso, colocamos em foco o fato do livro não possuir final ${ }^{7}$ e solicitamos que L. imaginasse um desfecho para a história e o escrevesse. A partir da comanda "escreva um final para a história", L. formula que a personagem Emil retorna para a casa de Elise no outro do dia e os dois brincam juntos.

\footnotetext{
${ }^{7}$ A escritora, Antje Damm, deixa claro, em entrevista concedida ao portal de notícias do Itaú Social, que concebe a leitura e o livro como possibilidade. Em suas palavras: "Devemos encontrar nos livros as possibilidades para fazer perguntas, iniciar discussões e conversas. O livro é o começo para um grande universo de perguntas" (DAMM, 2020), por isso, "A Visita" é uma história que não possui um final definido. Como sugere Damm (2020) "Um aspecto que considero significante neste livro é que a história não tem fim. Então, existe a possibilidade de as crianças entrarem na história e se tornarem parte dela”.
} 


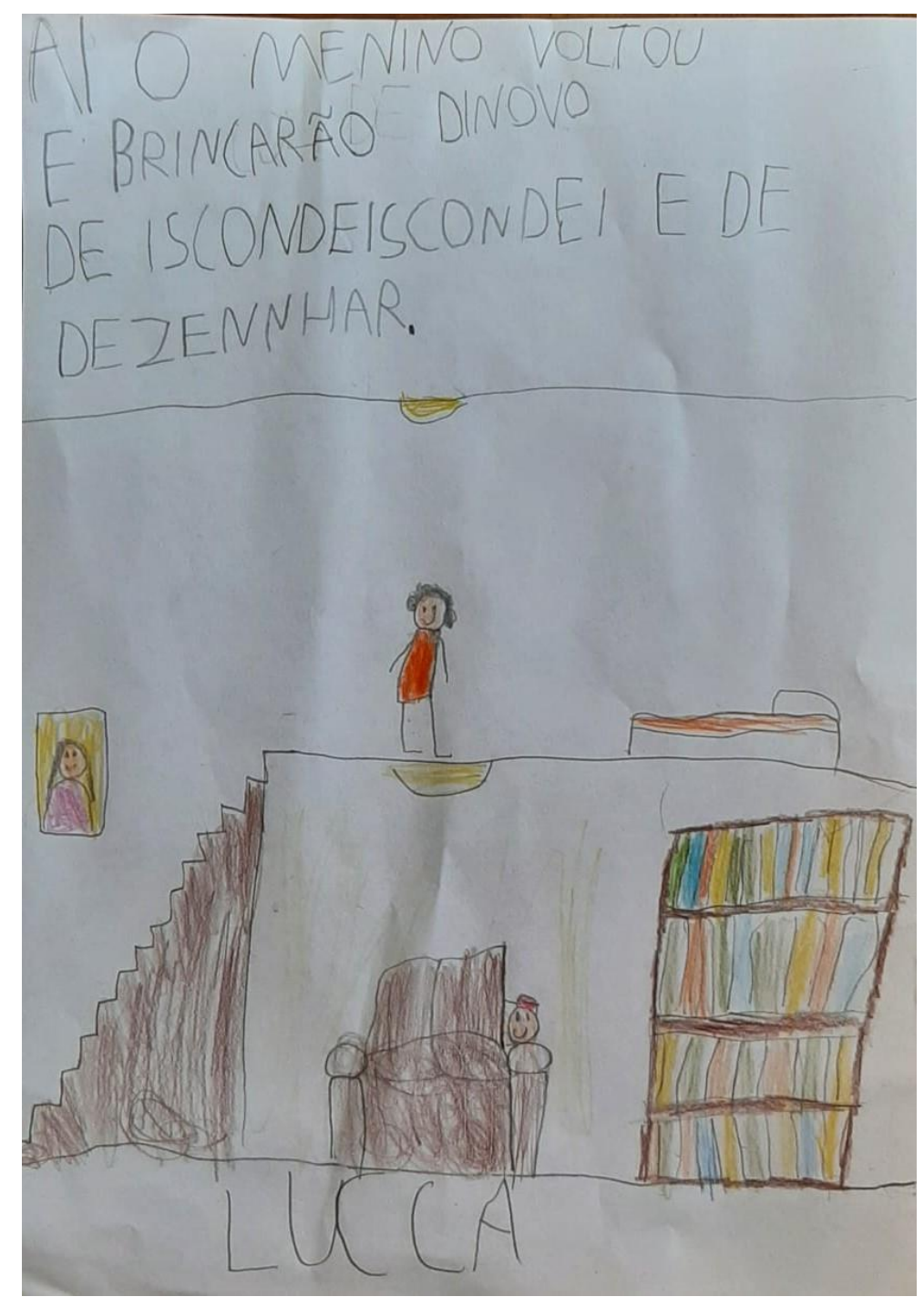

FIGURA 3 - Produção escrita de L.

Fonte: as autoras, pesquisa de campo.

Quando é dito que L. pode, ainda, desenhar seu final, L. acrescenta que os personagens, além de brincarem de esconde-esconde, desenharam. L. conclui sua produção perguntando para a pesquisadora se pode colocar um ponto final na história. A criança escreve e desenha seu final e, enquanto desenha, enumera quais elementos compõe a sua ilustração: um sofá, uma estante cheia de livros, Elise na parte superior da casa, em seu quarto, procurando por Emil, enquanto este se esconde atrás do sofá. L. desenha também a escada da casa de Elise, o quadro para o qual o menino aponta em determinado momento da narrativa, e, ao lado da escada, L. desenha uma biblioteca cheia de livros. Assim se encerra a conversa, que iniciou com uma história infantil e terminou com um novo final para ela, imaginado e construído dialogicamente por uma criança em processo de alfabetização.

Reflexões acerca do que foi relatado: o livro infantil e suas possibilidades 
Conhecer nosso leitor é imprescindível para analisarmos a sua produção como um texto singular, escrito a partir de uma prática de leitura contextualizada e fundamentada na teoria bakhtiniana. Por isso, trazemos para a nossa análise alguns dados biográficos que nos permitem entender quem o sujeito que se expressa e "fala" no texto em estudo. L. reside no município de Florianópolis e é estudante do Colégio de Aplicação da Universidade Federal de Santa Catarina (UFSC). Suas aulas neste período atípico consistem em encontros remotos síncronas, com um encontro semanal com a professora via videoconferência. Vale ressaltar que seu processo de alfabetização iniciou no ano de 2020, durante a pandemia causada pelo vírus Covid-19. Durante a interação, L. demonstrou se interessar por livros infantis e consumir literatura desde pequeno, sua mãe é professora formada em Letras e, além de ter experiência como alfabetizadora, é pesquisadora na área de alfabetização. Portanto, o contato de L. com a escrita e com livros infantis é estimulado desde sempre, a própria criança, durante a atividade, contou à pesquisadora que havia uma biblioteca com "milhares" de livros em sua casa. Tendo em vista 0 que apontam Camargos e Giovani (2020, p.171), voltamos nossos olhares para a produção de L., a fim de coletar nela os indícios que possibilitem refletir acerca da apropriação da modalidade escrita da língua. Os autores esclarecem que

[...] a língua materna, no que diz respeito à composição de seu léxico e de sua estrutura gramatical, não é apre(e)ndida pelo sujeito nos dicionários e nas gramáticas. Contrariamente, a adquirimos por meio de enunciados concretos que ouvimos e reproduzimos durante a comunicação viva, real que se efetua com indíviduos que nos rodeiam.

Dessa maneira, a partir da interação - mesmo virtual - baseada nos pressupostos dialógicos da teoria bakhtiniana, L. construiu seu texto. Nele é possível perceber que a criança já reconhece a relação existente entre grafemas e fonemas, ao perguntar, em determinado momento da atividade, se "voltou" é com "u" ou "l" e se "desenhar" é com "z" ou com "s", o que mostra um conflito com letras diferentes que representam o mesmo som. Dando sequência à nossa análise, percebemos que L. já possui uma noção sobre a pontuação dos textos escritos, ao perguntar para as pesquisadoras se poderia colocar um ponto final em seu texto, logo que 0 concluíra. Além disso, é importante refletir acerca do único sinal de rasura da escrita: em determinado momento da atividade, L. apaga algo que havia escrito e ao ser questionado sobre o porquê de estar apagando, ele afirma que cometera um erro, pois havia escrito "brincam", quando, na verdade, queria ter escrito "brincaram". Retomando o texto de L., observamos que esta palavra é grafada como "brincarão", ou seja, o verbo brincar está conjugado no futuro, o que demonstra que a criança ainda não distingue essas duas formas. 
Para além do domínio e conhecimento da estrutura da língua, podemos perceber no texto de L., que ele estabelece um diálogo com o livro infantil: atribuindo significado e dando sentido ao que foi lido. O texto já inicia com a palavra "ai", o que sugere que L. vai dar continuidade à história lida, respondendo, assim, à comanda dada pelas pesquisadoras. L., em sua produção, vai além da simples codificação da língua, pois a criança não repete, em seu texto, alguma parte da narrativa, ao contrário apropria-se do fato de os personagens terem brincado de esconde-esconde e escreve que, além de fazerem isso de novo no dia seguinte, também desenhariam juntos. A escolha específica da brincadeira - dentre todas as atividades realizadas pelas personagens no livro - pode ser um reflexo das preferências de nosso leitor, bem como, acrescentar uma nova atividade - a de desenhar - pode estar atrelada ao fato de ele estar desenhando no momento da atividade.

Logo, partindo para o desenho que acompanha e constitui uma unidade com o texto escrito, vemos que L. acrescenta um novo cômodo à casa de Elise: o seu quarto - que não é apresentado no livro - e desenha a estante de livros da personagem com vários livros que podem representar, também, a biblioteca que possui em sua casa. Outro detalhe importante em sua produção é o fato de que L. colore Elise com a cor vermelha. Isto é interessante para esta análise, pois o vermelho é usado para colorir Emil, enquanto Elise é representada com tons de cinza.

A cor, no livro infantil, como apontam Ferreira e Lino de Araújo (2015, p.2), "[...] assume papel de agente comunicador [...], apresentando informações não contidas no texto". Portanto, podemos interpretar a escolha de L. para colorir a sua ilustração da seguinte maneira: ao perceber que as cores das ilustrações que compõem a narrativa modificam ao longo do encontro entre as personagens, implicando que Elise perde seu medo - representado pela cor cinza - e abre-se para a amizade e para a brincadeira - representadas pelas tonalidades amarelas, rosa, verde e azul - L. atribui à Elise a cor que representa Emil, para indicar essa mudança na personagem.

Diante de tudo isso, é possível concluir que, em um movimento dialógico, L. apropria-se da palavra do outro, escrita dentro do livro, e a torna sua palavra.

\section{CONSIDERAÇÕES FINAIS}

Em um momento histórico como o que vivenciamos, em que a interação face a face foi substituída por telas, em que a escola foi incorporada pelo digital, é imprescindível tornar 0 ensino o mais humano possível. Encontramos na teoria bakhtiniana uma possibilidade de 
trabalhar a leitura e a escrita com crianças em alfabetização de maneira contextualizada, singular e humanizada. Como escrito na epígrafe que abriu este artigo, a prática de leitura - e de escrita - deve consolidar-se como atividade humana de constituição de sentidos. Ao contrário de simplesmente receber e decodificar a mensagem que lhe é transmitida, o leitor torna-se, no ato de ler, também autor do texto que é lido, ao colocar-se em diálogo com as palavras escritas, apropriar-se delas e dar-lhes novos tons e sentidos: o sujeito que lê constrói o texto ativamente. O caráter responsivo da leitura e da escrita deve ser colocado no centro das práticas de alfabetização, como meio de formar leitores, que dominam o código da escrita, mas que não somente decodificam o que está escrito. Assim, é possível refletir acerca da linguagem, acerca do sistema da língua e, principalmente, acerca da realidade.

Finalizamos este trabalho, ratificando o fato de que

[...] concebemos a autoria não como um lugar de abandono e solidão a que, muitas vezes, são submetidos os alunos em práticas escolares de escrita, mas como um modo de se relacionar com o texto que, por sua vez, é um modo de se relacionar com as pessoas e, consequentemente, com a própria existência. Nesta perspectiva, o texto produzido por um sujeito - autor - manifesta-se como o produto que busca estabelecer um determinado tipo de relação com o seu interlocutor (GIOVANI, 2010, p. 19).

Como evidenciado na produção textual aqui analisada, o livro infantil, quando trabalhado a partir da teoria enunciativa, se mostra um meio de constituição da subjetividade, da autonomia e da cidadania dos sujeitos que estão "aprendendo a ler e a escrever". A prática de leitura e escrita desenvolvida como um acontecimento (GERALDI, 2010, p.101) teve como objetivo final a compreensão e a interpretação do livro que foi lido e a elaboração de um texto que se adequasse à situação de interação proposta. Construir atividades que explorem o livro de literatura infantil como espaço de interação proporciona, dentro do ambiente virtual, não somente o desenvolvimento de habilidades de decodificação e codificação do sistema escrito, mas a apropriação da própria cultura escrita, bem como a formação de leitores reflexivos autores de seus dizeres.

\section{REFERÊNCIAS}

BAKHTIN, Mikhail. Os Gêneros do Discurso. In: Estética da criação verbal. 2.ed. São Paulo: Martins Fontes, 1997.

BAKHTIN, Mikhail. Notas sobre literatura, cultura e ciências humanas. São Paulo: Editora 34, 2017 
BRANDÃO, Helena Nagamine. Escrita, Leitura, Dialogicidade. In: BRAIT, Beth (Org.). Bakhtin: dialogismo e construção do sentido. 2.ed. Campinas: Editora da UNICAMP, 2005. p. 265-273

CAMARGOS, Moacir Lopes de; GIOVANI, Fabiana. Reexistencia e portunhol: fronteira e linguagem no contexto da pandemia de Covid 19. In: GEGe (Org.). Palavras e contrapalavras: cadernos de estudos XII. 1.ed. São Carlos: Pedro \& João editores, 2020.

CERUTTI-RIZZATTI, Mary Elizabeth. A apropriação da escrita como instrumento cultural. In: FLORIANÓPOLIS. VI Congresso de Educação Básica, 2016.

DAMM, Antje. A Visita. 1.ed. São Paulo: Companhia das Letrinhas, 2016.

DAMM, Antje. Filosofar com crianças é fazer perguntas sem dar respostas [entrevista concedia a] Kadija de Paula, Itaú Social: Notícias, [S.I.], Nov. 2020. Disponível em: < https://www.itausocial.org.br/noticias/antje-damm-filosofar-com-criancas-e-fazerperguntas-sem-dar-respostas/>. Acesso em: 25 Fev. 2021. FERREIRA, Anália Adriana da Silva; LINO DE ARAÚJO, Denise. A cor como elemento narrativo no livro infantil. Anais Eletrônicos do Selimel, 2015.

FREIRE, Paulo. Pedagogia da Autonomia: saberes necessário à prática educativa. 25.ed. São Paulo: Paz e Terra, 1996.

GERALDI, João Wanderley. Prática de leitura na escola. In: 0 texto na Sala de aula. 3.ed. São Paulo: Ática, 2010a.

GERALDI, João Wanderley. A aula como acontecimento. In: A aula como acontecimento. São Carlos: Pedro \& João Editores, 2010b.

GERALDI, João Wanderley. Heterocientificidade nos estudos linguísticos. In: GEGe. Palavras e contrapalavras: enfrentando questões da metodologia bakhtiniana. São Carlos: Pedro \& João editores, 2012.

GIOVANI, Fabiana. 0 texto na apropriação da escrita. 147 f. Dissertação (Mestrado) Programa de Pós Graduação em Educação, Centro de Ciências Humanas, Universidade Federal de São Carlos, 2006.

GIOVANI, Fabiana. Coeduca: o enfoque prático da alfabetização como um processo discursivo. São Carlos: PNAIC UFSCar, 2019.

GINZBURG, Carlo. Sinais: raízes de um paradigma indiciário. In: Mitos, emblemas e sinais. São Paulo: Companhia das Letras, 1989.

GOULART, Cecília M. A.. O conceito de letramento em questão: por uma perspectiva discursiva da alfabetização. Bakhtiniana, São Paulo, v.9, n.2, p.35-51, Ago./Dez. 2014.

INDURSKY, Freda. Estudos da linguagem: a leitura sob diferentes olhares teóricos. In: TFOUNI, Leda Verdiani (Org.). Lertramento, Escrita e Leitura. Campinas: Mercado das Letras, 2010.

PAIVA, Silvia Cristina Fernandes; OLIVEIRA, Ana Arlinda. A literatura infantil no processo de formação do leitor. Cadernos da Pedagogia, São Carlos, v.4, n.7, p. 22-36, Jan./Jun. 2010. 
QUEIROZ, Hélen A. 0 jogo literário: espaço, função e reverberação da literatura na formação do leitor na infância. 140 f. Dissertação (Mestrado), Programa de Pós-graduação em Educação, Faculdade de Educação, Universidade Federal do Rio de Janeiro, 2012.

SOBRAL, Adail. Interfaces entre Texto, Discurso e Gênero nos estudos da linguagem: uma perspectiva bakhtiniana. In: FIGUEIREDO, D. C.; BONINI, A.; FURLANETTO, M. M.; MORITZ, M. E. (Orgs.). Sociedade, Cognição e Linguagem: apresentações do IX CELSUL.

Florianópolis: Insular, 2012. 